\title{
Enhancement of ventilation efficiency in residential buildings by pulsating air-flow
}

\author{
Ronny Mai, Ralph Krause, Christian Friebe \\ INSTITUT FÜR LUFT- UND KÄLTETECHNIK gGmbH, Bertolt-Brecht-Allee 20, 01309 Dresden, Germany
}

\begin{abstract}
Contrary to conventional air-conditioning systems in non-residential buildings, the air-flow conditions are almost never considered in ventilation systems for residential buildings. Both the air inlets and the outlets are usually located at unfavourable places. This situation culminates in large buildings with many flats, where simplest supply-air apertures are installed with respect to cost restrictions. With small air flow rates, the ventilation efficiency is very poor due to a lack of air mixture. In order to improve the situation, a new supply air aperture has been developed recently. The air flow rate is designed to vary with time, with a low auxiliary energy requirement, with clear maxima and otherwise reduced flow rate. Hence, the corresponding momentum was expected to improve the air mixture in the room. First measurements confirm that the transient flow conditions allow high intrusion depths and a good mixing of the air. The pulsating airflow reduces the risk of draughts and increases both ventilation efficiency and thermal comfort in the living area. Moreover, the energy efficiency is improved as the average air-flow rate can be reduced.
\end{abstract}

\section{Introduction}

In order to increase the comfort and to improve the ventilation efficiency in residential buildings, an air outlet is to be developed that allows pulsating air supply. This increases the ventilation efficiency in the room and reduce the draught risk in the living area.

The advantage of the discontinuous mode of operation is that even very small amounts of air with sufficiently high impulses can be entered into the living area as a results of operation being interrupted for a period of time. Thus, a good ventilation efficiency is achieved without increasing the volume of supply air.

The pulsating air flow device should preferably be operated without auxiliary power and use the mechanical energy of the central fan for the changeover process. In a first attempt, the pulsating mode of operation is realized by a constructive solution approach with a rotatably mounted disk.

\section{Constructive and technical boundary conditions}

Derived from numerical flow simulations and market investigations, the subsequent technical parameters of the air outlet have been defined:

- (average) nominal air volume flow rate at the design point $20 \mathrm{~m}^{3} / \mathrm{h}$

- effective air volume range $10 \ldots 30 \mathrm{~m}^{3} / \mathrm{h}$ (optimized for domestic ventilation)

- (average) pressure loss $<50 \mathrm{~Pa}$ at nominal air flow rate
- nominal diameter DN 100

- preferably suitable for wall installation

- perforated metal cover (from acoustic and optical point of view, protective function)

- Pulse rate $<10 \mathrm{~min}^{-1}$.

The rotating disc allows to be switch the air flow between the axial and radial direction. The volume flow rate of the supply air is constant over time. Furthermore, there is no disturbing influence on the air duct system. Fig 1 depicts the principal air flow modes into the room.

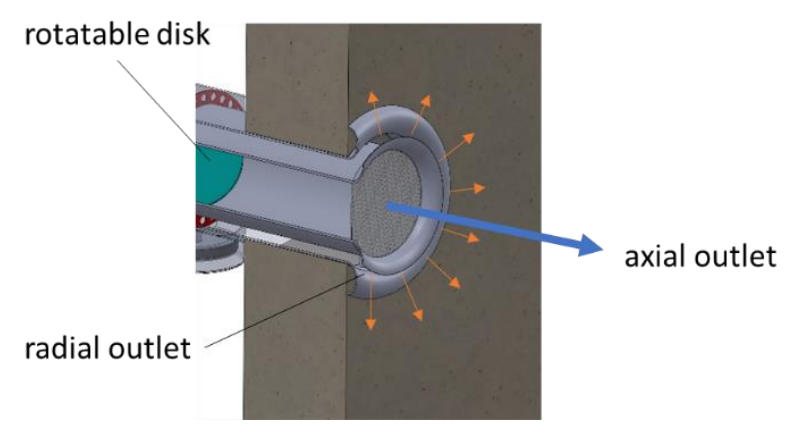

Fig 1. Principle air flow modes and construction design in solidworks

\section{Measurements}

Initially, a test rig was set up to allow a motor-driven pulsation with a mean flow rate of $25 \mathrm{~m}^{3} / \mathrm{h}$ at different pulse rates with different amplitudes (Fig 2). It contains a

\footnotetext{
* Corresponding author: ronny.mai@,ilkdresden.de
} 
mass flow measuring system for transient volumetric flow measurement and a 3D flow meter for three-dimensional velocity and turbulence measurement.

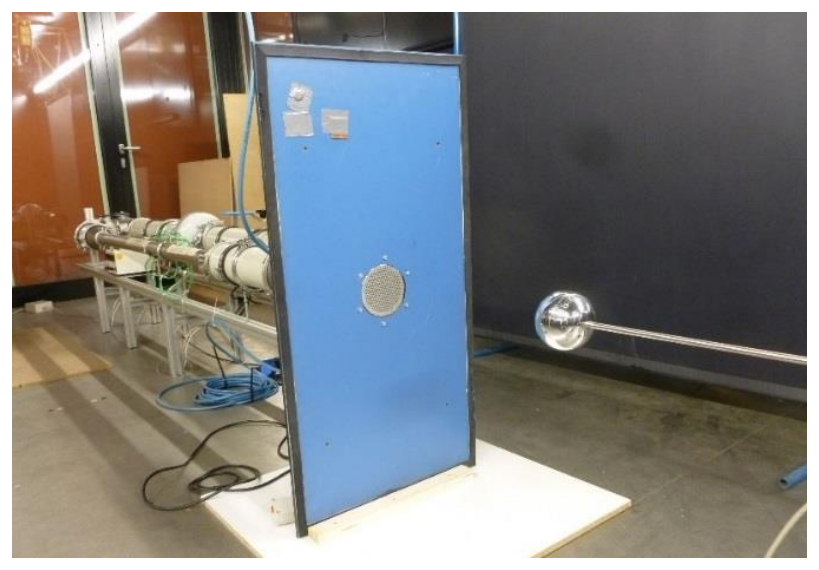

Fig 2. Test rig with $3 \mathrm{D}$ velocity meter

Thus, different outlet geometries (free jet with perforated plate, disc valve) and pulse rates $\left(7.6 \mathrm{~min}^{-1}\right.$, $25.8 \mathrm{~min}^{-1}, 63,2 \mathrm{~min}^{-1}$, constant) were examined in each case in comparison with the stationary mode of operation (Fig 3).
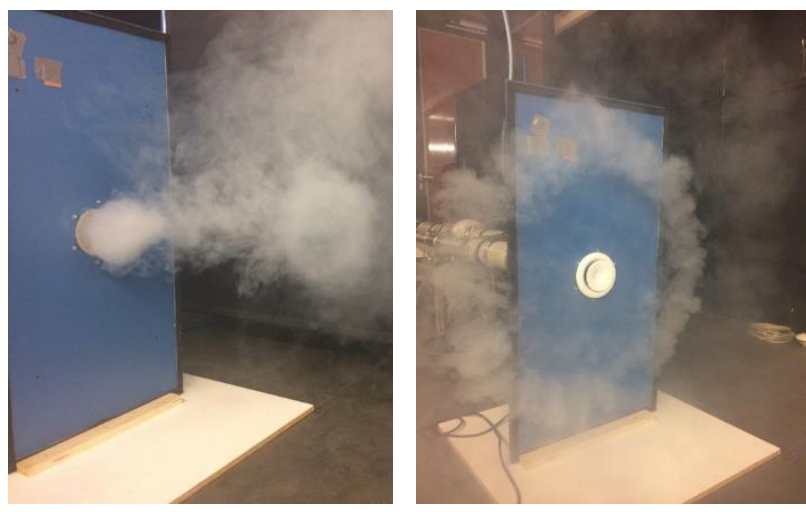

Fig 3. pulsating operation with perforated plate outlet (left) and disc valve (right)

At defined vertical and horizontal distances from the outlet, velocity and turbulence distribution were measured. Fig 4 presents a comparison of the velocities in the horizontal plane (x-direction) at the middle axis of the outlet. Settings with low pulse rates $\left(7.6 \mathrm{~min}^{-1}, 25.8 \mathrm{~min}^{-}\right.$ $\left.{ }^{1}\right)$ lead to higher velocities, especially at a far distances to the outlet compared to constant volume flow rate. Contrary, the high pulse rate $\left(63.2 \mathrm{~min}^{-1}\right)$ leads to only a slightly lower speed.

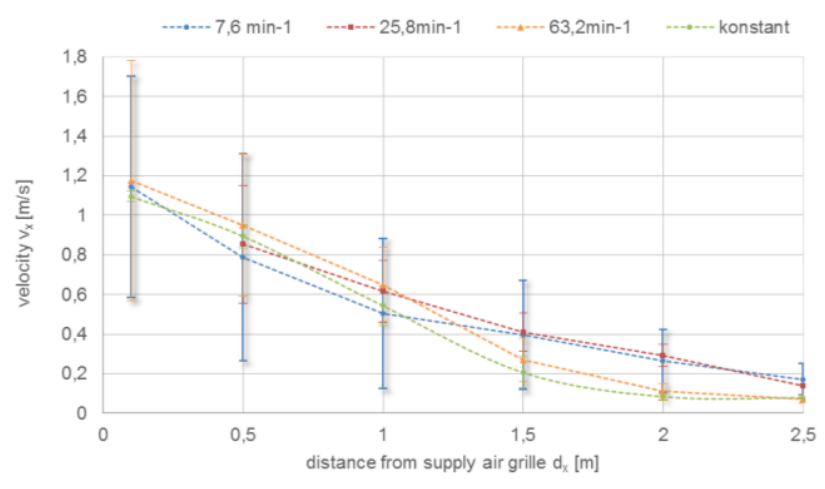

Fig 4. Comparison of velocities $v_{x}[\mathrm{~m} / \mathrm{s}]$ in isothermal operation mode (perforated plate, horizontal plane in the middle of the outlet)

The isotaches for $\mathrm{v}_{\mathrm{x}, \mathrm{m}}=0.2 \mathrm{~m} / \mathrm{s}$ in constant operation mode and in pulsation mode $\left(7.6 \mathrm{~min}^{-1}\right)$ are presented in Fig 5. The intrusion depth according to $\mathrm{v}_{\mathrm{x}, \mathrm{m}}=0.2 \mathrm{~m} / \mathrm{s}$ increases by $50 \%$ in pulsation mode.

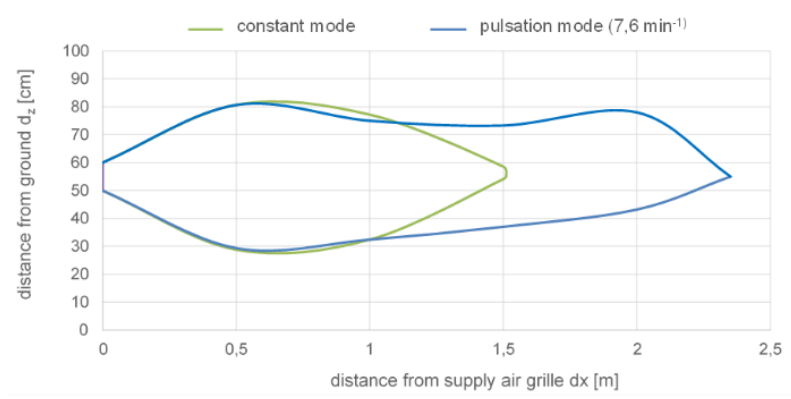

Fig 5. Comparison of the isotaches for $\mathrm{v}_{\mathrm{x}, \mathrm{m}}=0.2 \mathrm{~m} / \mathrm{s}$ in isothermal operation (perforated plate)

Visualisation of the flow patterns had been performed the test laboratory of ILK Dresden by means of a laser and aerosol (Fig 6). The laser light sheet was placed in the axis of the air outlet.

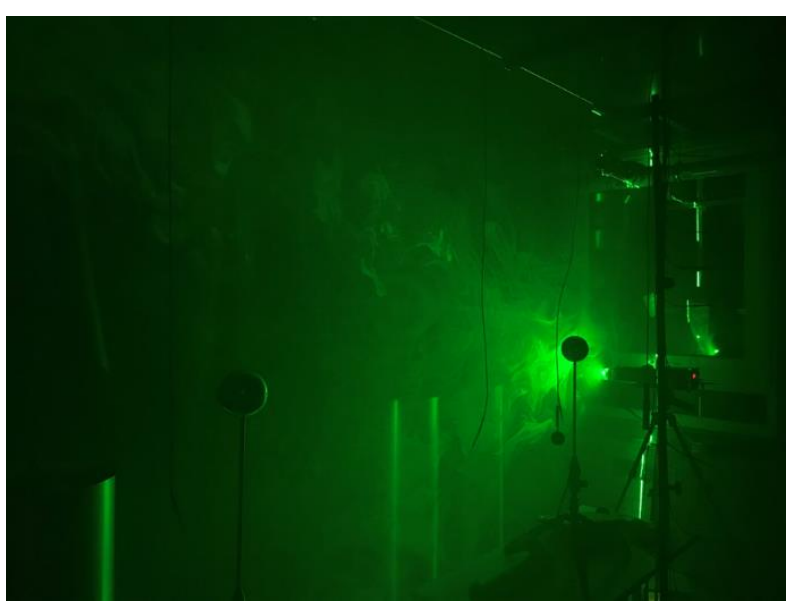

Fig 6. Visualization of the flow patterns by means of a laser

The flow velocities were recorded with the $3 \mathrm{D}$ velocity meter simultaneously. The aim was to measure the effects of a transient air flow in the immediate area of the room user. 
The experiments have clearly confirmed the function of the air outlet. Fig 7 depicts the different operating modes. Fig 7 a.) presents the axial outflow and the formation of a plume in the $x$-axis (maximum mode). Fig 7 a.) presents radial mode (low flow mode) with high velocity components in the $\mathrm{y}$ - and z-direction.

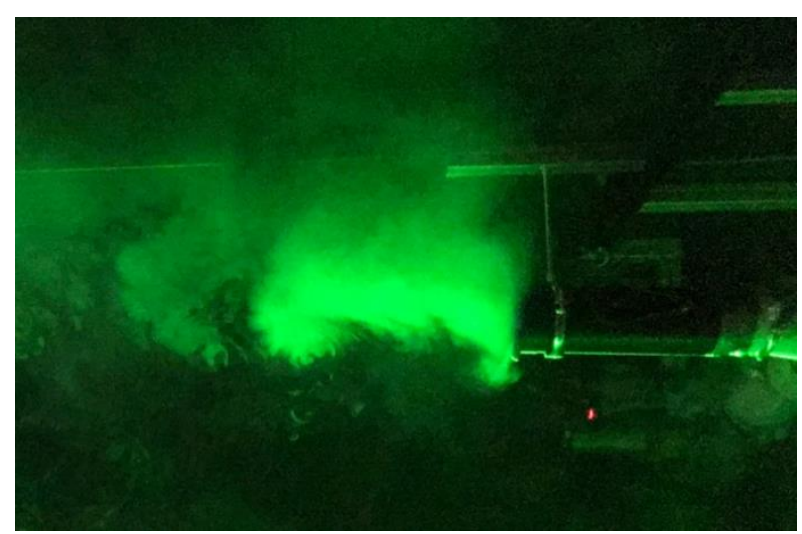

a.)

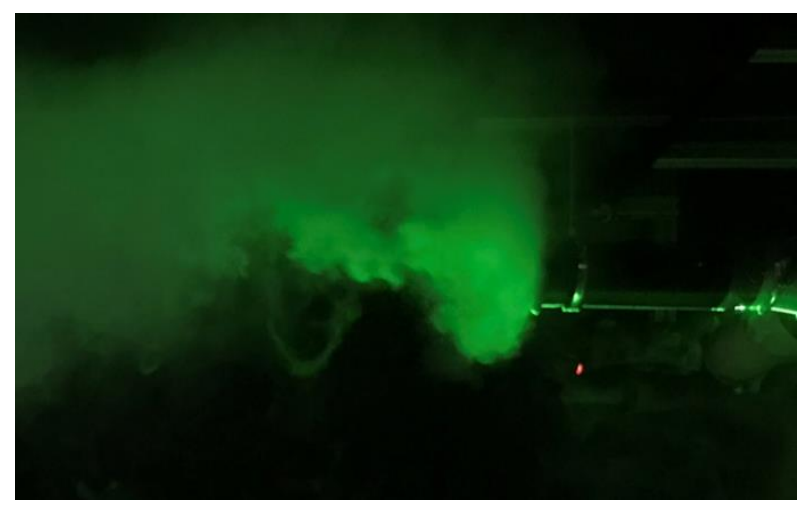

b.)

Fig 7. Flow pattern with axial (top) and radial (bottom) outlet

\section{Conclusion}

The presented investigations proof that the intrusion depth of a supply air stream into the room can be increased by a pulsating mode of operation. This may lead to a higher ventilation efficiency in rooms, where only small air flow volume rates are needed (e.g., residential rooms). Furthermore, it could be verified that the average air velocities do not negatively influence the comfort of the users.

Currently, a prototype is under construction that transfer the development into a real functional sample.

\section{Acknowledgements}

The research project is funded by the German Federal Ministry of Economic Affairs and Energy (BMWi) under the title "Pulsation Air outlet for home ventilation" (MF931125).

\section{Supported by:}

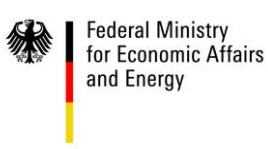

on the basis of a decision by the German Bundestag 